\title{
CRITICAL SUCCESS FACTORS-BASED CONTENT MANAGEMENT SYSTEM DEVELOPMENT FOR SMALL AND MEDIUM SIZE ENTERPRISES
}

\author{
${ }^{1}$ Yulius Lie and ${ }^{2}$ Bens Pardamean \\ ${ }^{1}$ School of Information Systems, Bina Nusantara University, West Jakarta, Indonesia \\ ${ }^{2}$ Graduate School of Information Systems, Bina Nusantara University, West Jakarta, Indonesia
}

Received 2014-03-12; Revised 2014-04-27; Accepted 2014-06-26

\begin{abstract}
The purpose of this study is to compare the sales and visitor access traffic as a result of using critical success factors in an online car accessories store compared with online trading forums. The study uses quantitative and non-experimental methods. Quantitative data analysis and t-test are performed on the comparison and correlation of visitor access and sales frequency between online stores and online trading forums. Analysis results show visitor access traffic and sales frequency in online trading forums are significantly higher than online stores. This study revealed that it is better to market and sell car accessories online through online trading forums compared to a specialized online store.
\end{abstract}

Keywords: Content Management System, Critical Success Factors, Online Store, Online Forum

\section{INTRODUCTION}

Along with the need for practicality in modern systems, current trade is not only performed physically but also through the Internet or in what we know as ecommerce. The number of individual buyers of online products and services still continues to increase despite resistance toward these online-based purchasing systems (Hansen, 2008). The existence of Small and Medium Enterprises (SME) is crucial due to its important role in the commercial sector. Their main obstacle is generally lack of capital and difficulties in marketing (Rangone, 1999; Tambunan, 2009). Currently there is a lot of SMEs engaged in automotive sales more particularly car accessories via an online channel. Sales of car accessories in the Internet are more commonly performed in general trading forums or special automotive forums. Departing from this fact, the authors developed an online store selling car accessories as an SME media by using a Content Management System (CMS) website based on critical success factors. The selection of CMS usage was due to shorter development time and lower development costs. These were considered as the advantages of using CMS. This study also compared sales and visitor access between the developed online store with threads selling car accessories in online trading forums to determine the best media for online sales of car accessories.

Currently there is not many Small and Medium Enterprises (SMEs) performing its operations online due to slow adoption of e-commerce on SMEs (Simpson and Docherty, 2004), including those operating in the automotive sector, which implementation runs more in trading and market place forums as social media which acts as a container for interaction of the community using the role of social capital in possession (Cooke and Wills, 1999; Bowles and Gintis, 2002; Molina-Morales and Martinez-Fernández, 2010). The research questions were whether visitor access and sales at the online store developed with a content management system based on critical success factors is higher than online trading forums and the types of their relationship.

The purpose of this study was to compare visitor access traffic and sales as a result of applying CSF for SMEs

Corresponding Author: Yulius Lie, School of Information Systems, Bina Nusantara University, West Jakarta, Indonesia 
selling car accessories in an online store with online trading forums. The results would determine best options in marketing and selling car accessories online from the comparison between access traffic density and sales frequency in online stores and online trading forums.

\section{MATERIALS AND METHODS}

This study was performed using non-experimental quantitative methods. The development of an online store used PrestaShop, which is an open source Content Management System (CMS) widely used to build an online store as an e-commerce application. The study was conducted in the developed online store and car accessories sales thread in online trading forums with the population of all customers who may have Internet access to the online store within three months (August 1, 2013 until October 31, 2013).

The development of the online store was based on the definition of Critical Success Factors (CSF) as seen in Table 1 which served as a comparison of online stores with online trading forums. The features were views and navigation in which sellers can present an attractive product display to prospective buyers (Sahney, 2008; Behjati and Othaman, 2012) to build consumer trust and satisfaction (Cyr, 2008; Lin, 2007), provision of contact between the seller and the buyer that may bridge communication which is good for building buyer's trust (Sahney, 2008; Behjati and Othaman, 2012) which itself is a form of improved service to consumers, an advantage in the e-commerce system (April and Pather, 2008). References from previous customers in the form of testimonials may also be one of the factors to build buyers trust to make purchases thereafter (Behjati and Othaman, 2012; Chen, 2009) which in turn may build customer loyalty as a factor of acceptance of the e-commerce system (Al-Abdallah, 2013).
Sales frequency data collection was performed for the online store and for online forum threads based on orders from consumers. Visitor access traffic data collection at the online store was done with the help of Google Analytics and the use of a digital dashboard provided by Prestashop. Meanwhile data collection for online trading forums was performed by calculating the number of views in a thread. Data recording was made daily during the study period.

\section{RESULTS}

The Development of online store uses Prestashop as shown in Fig. 1 which is an open source Content Management System (CMS). Development starts with installation of Prestashop on the web, domain registration of the online store, selection of a web hosting provider and database creation. Content creation was performed through the dashboard of Prestashop (accessed using an administrator account).

Thread creation in the online trading forum was performed by registration of an account in the forum, selection of the appropriate category for products sold (car accessories) and inclusion of content in a forum thread. Contents that included images must be uploaded through third-party applications to obtain a code that was linked to the forum thread. Figure 2 depicts the threads in the online trading forum used in this study.

Table 2 shows the detail of sales frequency data analysis of online stores with sales from threads of online trading forums. Table 3 concludes the analysis of visitor access traffic data from the online store compared to the thread in online trading forums. Analysis results of visitor access traffic relationship to sales in the online store are shown in Table 4. Table 5 shows the analysis results of visitor access traffic relationship to sales in threads of the online trading forum.

Table 1. E-commerce critical success factors for online store and trading forum

\begin{tabular}{|c|c|c|}
\hline & Online store & Forum thread \\
\hline Layout and navigation & $\begin{array}{l}\text { Product is displayed in a table structure } \\
\text { (rows and columns) and product details } \\
\text { may be displayed in a different page }\end{array}$ & $\begin{array}{l}\text { Product is displayed vertically (rows) with } \\
\text { product details in the same page }\end{array}$ \\
\hline $\begin{array}{l}\text { Contact between seller } \\
\text { and customer }\end{array}$ & $\begin{array}{l}\text { Display of seller contact list (dial phone, } \\
\text { text messaging, e-mail), with live chat } \\
\text { feature (online messaging) }\end{array}$ & $\begin{array}{l}\text { Display of seller contact list (dial phone, } \\
\text { text messaging, e-mail), with private message feature }\end{array}$ \\
\hline Reference & Testimonial are placed in a special page & $\begin{array}{l}\text { Testimonial from previous buyer are placed } \\
\text { in thread according to posting time }\end{array}$ \\
\hline
\end{tabular}


Yulius Lie and Bens Pardamean / Journal of Computer Science 10 (10): 2055-2059, 2014

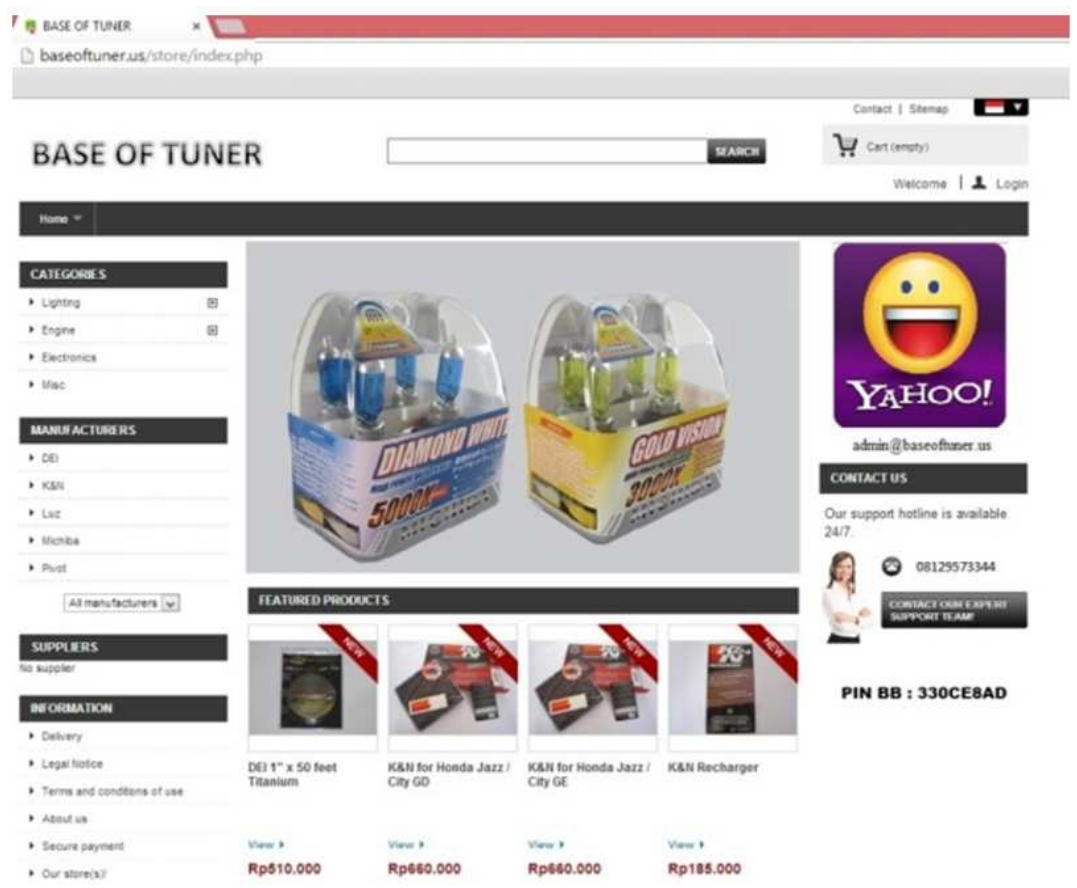

Fig. 1. Online store main page

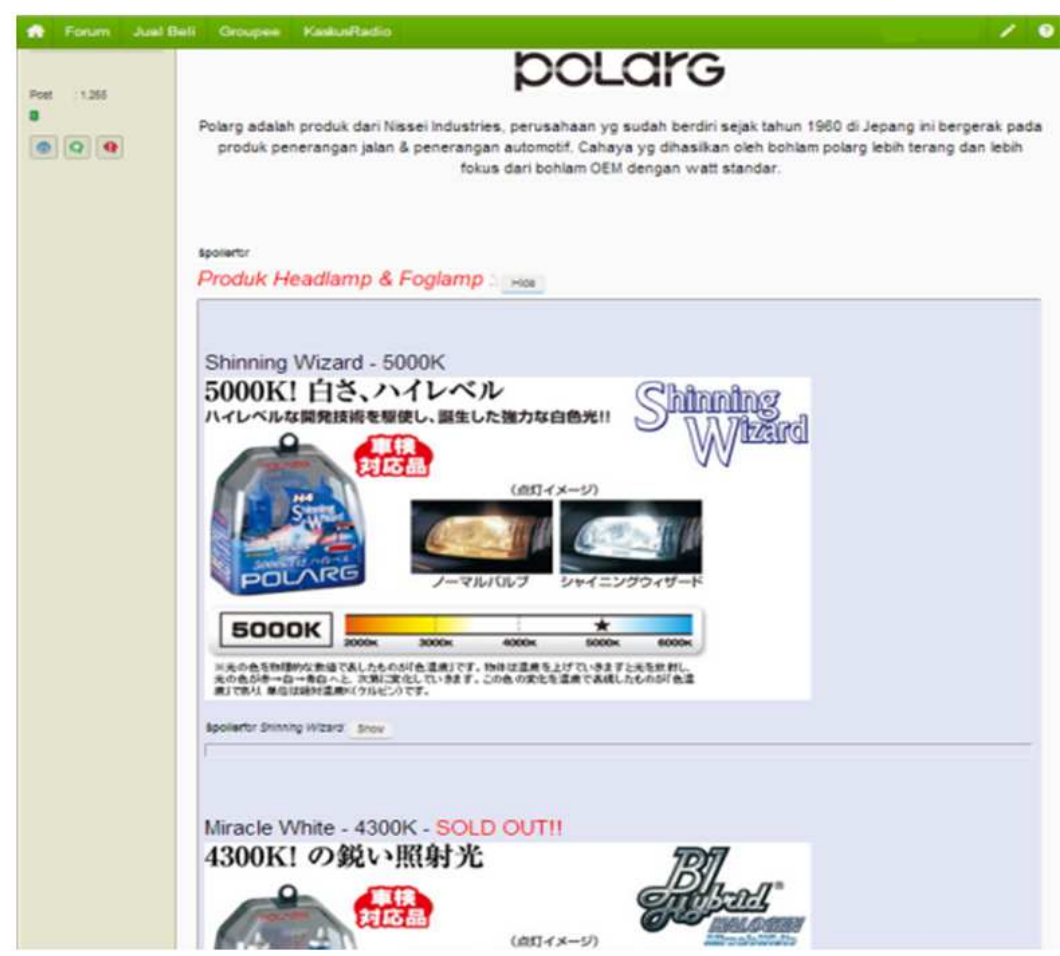

Fig. 2. An online transaction forum 
Nevertheless high visitor access traffic to threads in online trading forums does not affect sales frequency. This is due to many forum members who stopped by to view the product being sold but did not make a purchases.

\section{DISCUSSION}

With a p-value $<0.001$ in Table 2 which shows the detail of Sales frequency data analysis of online stores with sales from threads of online trading forums, it can be concluded that there is a significant difference between the sales frequency in the online store compared to sales frequency from threads in online trading forums. Sales in the online trading forums are significantly higher compared to the sales made in the online store developed with a Content Management System-based on critical success factors.

The analysis of visitor access traffic data from the online store compared to the thread in online trading forums in Table 3 has p-value $<0.001$. It can be concluded that there is a significant difference between the access traffic of the online store compared with access traffic of the online trading forum threads. Visitor access traffic in the online trading forum is significantly higher than compared to the online store developed with a Content Management System-based on critical success factors.

With a correlation coefficient of 0.253 and p-value equals 0.015 in Table 4 which shows the analysis results of visitor access traffic relationship to sales in the online store, it is concluded that there is a relationship between visitor access traffic with sales at the online store that is developed with a Content Management System-based on critical success factors.

Since the p-value is equal to 0.580 for a correlation coefficient of 0.058 from the analysis results of visitor access traffic relationship to sales in threads of the online trading forum in Table 5, it was concluded that there is no relationship between visitor access traffic to sales on online trading forum threads. Referring to the research data analysis, it is shown that there is a significant difference in the visitors access traffic and sales frequency in the online store compared to threads in the online trading forum, where access traffic and high sales occurred in the online trading forum. This is a picture of a high interaction in the forum in which the role of the community is used as the basis of the establishment of a discussion forum as well as online buying and selling.
Table 2. Sales frequency data

\begin{tabular}{lll}
\hline $\mathrm{N}=92$ & Mean $($ Std. deviation) & $\mathrm{p}$-value \\
\hline Online store & $0.78(0.900)$ & $<0.001$ \\
Trading forum & $1.39(1.382)$ & \\
\hline
\end{tabular}

Table 3. Access traffic data

\begin{tabular}{lll}
\hline $\mathrm{N}=92$ & Mean (Std. deviation) & $\mathrm{p}$-value \\
\hline Online store & $18.51(4.592)$ & $<0.001$ \\
Trading forum & $42.21(8.238)$ & \\
\hline
\end{tabular}

Table 4. Online store data correlation

\begin{tabular}{llr}
\hline Correlation of & \\
access traffic- & Correlation coefficient & p-value \\
sales $(\mathrm{N}=92)$ & 0.253 & 0.015 \\
\hline
\end{tabular}

Table 5. Forum data correlation

\begin{tabular}{lcc}
\hline Correlation of & & \\
access traffic- & Correlation coefficient & p-value \\
sales $(\mathrm{N}=92)$ & 0.058 & 0.580 \\
\hline
\end{tabular}

\section{CONCLUSION}

Based on the study that has been performed the researchers concluded that the best option in marketing and selling car accessories online is through online trading forums. Online selling strategy through an online community is quite effective in introducing products that are sold due to high traffic of visitors hence allowing access to significant sales by offering attractive products and it is also in accordance with the currently growing trend. Small and Medium Enterprises (SMEs) may take a glance at an online sales strategy to expand sales coverage so it is not limited to point of sale which may not be accessible to buyers from a far distance. This strategy is also quite effective for SMEs who are just starting in business as a means of introduction to business and its products with limited funding and a shorter time compared to opening physical stores. The choice of using Content Management System (CMS) in the development of an online store is a practical choice to overcome limitations in time, capital and programming skills.

\section{REFERENCES}

Al-Abdallah, G.M., 2013. The effect of customercompany relationship on internet adoption in Jordanian small and medium enterprises. J. Econ. Behavioral Stud., 5: 192-203. 
April, G.D. and S. Pather, 2008. Evaluating service quality dimensions within e-commerce SMEs. Electr. J. Inform. Syst. Evaluation, 11L: 109-124.

Behjati, S. and Othaman, 2012. What drives consumers online storeping. Conceptual review of online storeping attributes investigated in previous studies. Int. J. Contemp. Res. Bus., 3: 297-311.

Bowles, S. and H. Gintis, 2002. Social capital and community governance. Econ. J., 112: 419-436. DOI: $10.1111 / 1468-0297.00077$

Chen, W.S., 2009. Analysis of a customer satisfaction survey using rough sets theory a manufacturing case in Taiwan. Asia Pacific J. Marketing Logistics, 21: 93-105. DOI: 10.1108/13555850910926263

Cooke, P. and D. Wills, 1999. Small firms, social capital and the enhancement of business performance through innovation programmes. Small Bus. Econ., 13: 219-234. DOI: 10.1023/A: 1008178808631

Cyr, D., 2008. Modeling Web site design across cultures: Relationships to trust, satisfaction and e-loyalty. J. Manage. Inform. Syst., 24: 47-72. DOI: 10.2753/MIS0742-1222240402

Hansen, T., 2008. Consumer values, the theory of planned behaviour and online grocery shopping. Int. J. Consu. Stud., 32: 128-137. DOI: 10.1111/j.14706431.2007.00655.x
Lin, H.F., 2007. The impact of website quality dimensions on customer satisfaction in the B2C ecommerce context. Total Quality Manage., 18: 363378. DOI: $10.1080 / 14783360701231302$

Molina-Morales, F.X. and M.T. Martinez-Fernández, 2010. Social networks: Effects of social capital on firm innovation. J. Small Bus. Manage., 48: 258279. DOI: $10.1111 / \mathrm{j} .1540-627 X .2010 .00294 . \mathrm{X}$

Rangone, A., 1999. A resource-based approach to strategy analysis in small-medium sized enterprises. Small Bus. Econ., 12: 233-248. DOI: 10.1023/A:1008046917465

Sahney, S., 2008. Critical success factors in online retailan application of quality function deployment and interpretive structural modeling. Int. J. Bus. Inform., 3: 144-163.

Simpson, M. and A.J. Docherty, 2004. E-commerce adoption support and advice for UK SMEs. J. Small Bus. Enterprise Dev., 11: 315-328. DOI: 10.1108/14626000410551573

Tambunan, T., 2009. Export-oriented small and medium industry clusters in Indonesia. J. Enterprising Commun. People Places Global Econ., 3: 25-58. DOI: 10.1108/17506200910943661 